\title{
Synthesis and Polymerization of Methacrylate Having Fullerene
}

\author{
Hisaya Sato, Daichi Matsuda, and Kenji Ogino \\ Department of Material Systems Engineering, Faculty of Technology, Tokyo University of \\ Agriculture and Technology, Koganei, Tokyo 184-8588, Japan
}

(Received February 27, 1998)

\begin{abstract}
Two methacrylate monomers containing fullerene on the side chain (AHMA-C 60 or AEMA-C 60 ) were synthesized by reacting 4-azidobenzoyloxy-hexyl and -ethyl methacrylate, respectively, with fullerene. ${ }^{1} \mathrm{H}$ and ${ }^{13} \mathrm{C}$ NMR spectra of these monomers revealed each was a mixture of $[6,6]$ bridged azamethanofullerene derivative and azafulleroid derivative resulting from [5,6] additions. The monomers were later copolymerized with $t$-butyl methacrylate. In the case of anionic copolymerization using a Grignard reagent, the monomers were incorporated in the polymer chain via vinyl chain reactions, resulting in a charm bracelet type fullerene polymer. The copolymer composition was found almost equal to the composition of monomers fed. In radical copolymerizations, low molecular weight oligomers were obtained in low yields, and contained almost equal amounts of the vinyl group to the fullerene monomer incorporated in the polymer, indicating that the fullerene unit played a role of an inhibitor or a degradative chain transfer agent.

KEY WORDS Fullerene/Methacrylate/Anionic Copolymerization/RadicalCopolymerization/Charm Bracelet / Azafulleroid / Azamethanofullerene /
\end{abstract}

[60]Fullerene $\left(\mathrm{C}_{60}\right)$ was first detected by Kroto et al. in $1985 .^{1}$ But it was only after the establishment of large scale synthesis by Kratschmer et al. ${ }^{2}$ in 1990 , that the fullerene was isolated and its structure/properties relations were studied. Since then, many interesting properties of fullerene have been found. The continuous photoconductivity of a polymer could be increased by doping fullerene. ${ }^{3}$ Fullerene is also used as charge generation material ${ }^{4}$ and shows ferromagneticity by forming charge transfer complex with tetrakis-(dimethylamino)ethylene, ${ }^{5}$ Thus, fullerene is expected to have a potential for new functional materials.

Fullerene and its low molecular weight derivatives are difficult to fabricate and, many works on the preparation of polymeric materials containing fullerene have been done. Polymers containing fullerene units are polyfullerene in which fullerene molecules are connected by covalent bonds, pearl necklace type polymer in which fullerene is incorporated in the main chain of a polymer, and charm bracelet type polymer in which fullerene is attached to the side chain. ${ }^{6}$ Polyfullerene was obtained by irradiating strong ultraviolet (UV) light to fullerene film to polymerize the fullerene molecules. ${ }^{7}$ As polymers having fullerene in the main chain, a copolymers of fullerene and $p$-xylylene, ${ }^{8}$ products obtained by the reaction of fullerene with $\alpha, \omega$-diamino functionalized polymers $^{9}$ have been reported. Polyamides were synthesized by the direct copolycondensation of a mixture of fullerenobisacetic acid and isophthalic acid with 4,4'diaminodiphenyl ether, ${ }^{10}$ and polyesters were prepared by reaction of fullerene bisphenol with dibasic acid dichloride. ${ }^{11}$ Radical copolymerizations of styrene or methyl methacrylate with fullerene provide low molecular weight pearl necklace type polymers. ${ }^{12}$ Charm bracelet polymers are prepared from bis(hydroxyphenyl)- ${ }^{13}$ or bis(fluorophenyl)-methanofullerene ${ }^{14}$ by polycondensation or polyaddition reaction. This polymer is synthesized by reacting fullerene with poly(styreneco-azidemethylstyrene) ${ }^{15}$ or polyethyleneimine. ${ }^{16}$ Since fullerene is polyfunctional, cross-linked polymers are often obtained. A charm bracelet polymer is expected to be obtained by the polymerization of a vinyl monomer containing fullerene unit. However, due to high reactivity of fullerene unit to an initiator or to other active chain ends, no investigation has been done on the vinyl polymerization of fullerene containing monomer as far as we know.

In this report methacrylate type monomers having fullerene unit were prepared by reacting 6-(4-azidobenzoyloxy)hexamethyl- or 2-(4-azidobenzoyloxy)ethyl methacrylates with fullerene. These monomers were copolymerized with $t$-butyl methacrylate using Grignard reagent as an initiator. The structure of the copolymer was investigated in relation to the copolymer prepared by radical copolymerization.

\section{EXPERIMENTAL}

\section{Materials}

[60]Fullerene $\left(\mathrm{C}_{60}\right)$ was obtained from Southern Chemical Group (purity $>99.5 \%$ ), and used without further purification. Bromobenzene, chlorobenzene, tetrahydrofuran, $t$-butyl methacrylate ( $t$-BMA), and triethylamine were commercially obtained, and purified by distillation before use. Other reagents were obtained commercially, and used without further purification.

\section{Synthesis of Monomers}

6-Hydroxyhexyl Methacrylate (1). In a $300 \mathrm{ml}$ roundbottom ice-cooled flask, were placed $150 \mathrm{ml}$ of dry tetrahydrofuran (THF), $14.0 \mathrm{ml}(100 \mathrm{mmol})$ of triethylamine and $27.0 \mathrm{~g}$ (228 mmol) of 1,6-hexanediol. $12.5 \mathrm{ml}$ $(112 \mathrm{mmol})$ of methacryloyl chloride were added dropwise into the flask with stirring. The reaction was allowed to stand overnight at room temperature. The mixture was filtered to remove insoluble material, washed thoroughly with water three times, and dried with anhydrous magnesium sulfate. The solvent was removed by evaporation. The desired product was obtained in $51 \%$ yield after purification by column chromatography using silica gel and chloroform. ${ }^{1} \mathrm{H}$ NMR $\left(\mathrm{CDCl}_{3}\right) 6.10$ $\left(\mathrm{m}, 1 \mathrm{H}, \mathrm{CH}_{2}=\right), 5.55\left(\mathrm{~m}, 1 \mathrm{H}, \mathrm{CH}_{2}=\right), 4.15(\mathrm{t}, 2 \mathrm{H}$, 
$\left.\mathrm{COOCH}_{2}-\right), 3.65\left(\mathrm{t}, 2 \mathrm{H},-\mathrm{CH}_{2} \mathrm{OH}\right), 1.95(\mathrm{~m}, 3 \mathrm{H}$, $\left.=\mathrm{C}\left(\mathrm{CH}_{3}\right)\right), 1.90(\mathrm{~s}, 1 \mathrm{H},-\mathrm{OH}), 1.70\left(\mathrm{~m}, 2 \mathrm{H},-\mathrm{COOCH}_{2}-\right.$ $\left.\mathrm{CH}_{2}-\right), 1.60\left(\mathrm{~m}, 2 \mathrm{H},-\mathrm{CH}_{2} \mathrm{CH}_{2}-\mathrm{OH}\right), 1.42(\mathrm{~m}, 4 \mathrm{H}$, $\left.-\mathrm{OCH}_{2} \mathrm{CH}_{2}\left(\mathrm{CH}_{2}\right)_{2} \mathrm{CH}_{2} \mathrm{CH}_{2} \mathrm{O}-\right)$.

4-Azidophenylbenzoyl Chloride (2). In a $50 \mathrm{ml}$ roundbottom flask, $3.00 \mathrm{~g}$ (18.4 mmol) of 4-azidobenzoic acid were suspended in $30 \mathrm{ml}(413 \mathrm{mmol})$ of thionyl chloride under a nitrogen atmosphere. The suspension was refluxed for $4 \mathrm{~h}$ to turn it to a clear solution. 2 was obtained after removing the excess thionyl chloride by distillation. This product was immediately used in the next esterification reaction without further purification.

6-(4-Azidobenzoyloxy)hexyl Methacrylate (4). In a $200 \mathrm{ml}$ round-bottom flask, were placed $70 \mathrm{ml}$ of dry chloroform, $6.0 \mathrm{ml}(43 \mathrm{mmol})$ of trietylamine, and $2.27 \mathrm{ml}$ (18.0 mmol) of 6-hydroxyhexyl methacrylate. A solution of $3.34 \mathrm{~g}(18.4 \mathrm{mmol})$ of 4-azidobenzoyl chloride in $30 \mathrm{ml}$ of chloroform was added dropwise while stirring the contents and cooling the flask in an ice water bath. The reaction mixture was stirred overnight at room temperature. The mixture was filtered to remove insoluble material and washed three times with water. After drying over anhydrous magnesium sulfate, evaporating and purifying by column chromatography (silica gel, toluene), $5.43 \mathrm{~g}$ of the desired product 4 were obtained in $91 \%$ yield. ${ }^{1} \mathrm{H} \mathrm{NMR}\left(\mathrm{CDCl}_{3}\right) 8.05$ (d, 2H, Ar), 7.05 (d, 2H, Ar), $6.10\left(\mathrm{~m}, 1 \mathrm{H}, \mathrm{CH}_{2}=\right), 5.55\left(\mathrm{~m}, 1 \mathrm{H}, \mathrm{CH}_{2}=\right)$, $4.35\left(\mathrm{t}, 2 \mathrm{H},-\mathrm{CH}_{2}-\mathrm{OC}(=\mathrm{O})-\mathrm{Ar}\right), 4.15\left(\mathrm{t}, 2 \mathrm{H}, \mathrm{CH}_{2}=\right.$ $\left.\mathrm{C}\left(\mathrm{CH}_{3}\right)-\mathrm{COOCH}_{2}-\right), 1.95\left(\mathrm{~m}, 3 \mathrm{H},=\mathrm{C}\left(\mathrm{CH}_{3}\right)\right), 1.6-1.8$ $\left(\mathrm{m}, 4 \mathrm{H},-\mathrm{OCH}_{2} \mathrm{CH}_{2}-\right), 1.42\left(\mathrm{~m}, 4 \mathrm{H},-\mathrm{OCH}_{2} \mathrm{CH}_{2}-\right.$ $\left.\left(\mathrm{CH}_{2}\right)_{2} \mathrm{CH}_{2} \mathrm{CH}_{2} \mathrm{O}-\right)$.

2-(4-Azidobenzoyloxy)ethyl Methacrylate (3). Following the procedure above, 3 was prepared from 4-azidobenzoyl chloride and 2-hydroxyethyl methacrylate in $90 \%$ yield. ${ }^{1} \mathrm{H} \mathrm{NMR}\left(\mathrm{CDCl}_{3}\right) 8.05$ (d, 2H, Ar), 7.05 (d, $2 \mathrm{H}, \mathrm{Ar}), 6.13\left(\mathrm{~m}, 1 \mathrm{H}, \mathrm{CH}_{2}=\right), 5.58\left(\mathrm{~m}, 1 \mathrm{H}, \mathrm{CH}_{2}=\right)$, $4.4-4.6\left(\mathrm{~m}, 4 \mathrm{H},-\mathrm{OCH}_{2} \mathrm{CH}_{2} \mathrm{O}-\right), 1.95(\mathrm{~m}, 3 \mathrm{H}$, $\left.=\mathrm{C}\left(\mathrm{CH}_{3}\right)\right)$.

$A H M A-C_{60}$ (6). In a $200 \mathrm{ml}$ round-bottom flask, $500 \mathrm{mg}(0.69 \mathrm{mmol})$ of $\mathrm{C}_{60}$ and $200 \mathrm{mg}(0.73 \mathrm{mmol})$ of 6-(4-azidobenzoyloxy)hexyl methacrylate were placed and dissolved in $100 \mathrm{ml}$ of chlorobenzene under a nitrogen atmosphere. The reaction mixture was refluxed for a prescribed time. After evaporation of the solvent, the residue (black powder) was purified by column chromatography (silica gel, toluene). Unreacted $\mathrm{C}_{60}$ eluted out first followed by the elution of 6. Products with more than two methacrylate units were strongly adsorbed. The eluent was evaporated and remaining residue (dark brown powder) was washed with methanol and hexane. After drying under vacuum, the product 6 was obtained in $17 \%$ yield as dark brown powders. ${ }^{1} \mathrm{H}$ NMR $\left(\mathrm{CDCl}_{3}\right)$ 8.21, 8.10 (dd, 2H, Ar), 7.75, 7.56 (dd, $2 \mathrm{H}, \mathrm{Ar}), 6.10\left(\mathrm{~m}, 1 \mathrm{H}, \mathrm{CH}_{2}=\right), 5.57\left(\mathrm{~m}, 1 \mathrm{H}, \mathrm{CH}_{2}=\right), 4.38$ $\left(\mathrm{t}, 2 \mathrm{H},-\mathrm{CH}_{2}-\mathrm{OC}(=\mathrm{O})-\mathrm{Ar}\right), 4.18\left(\mathrm{~m}, 1 \mathrm{H}, \mathrm{CH}_{2}=\mathrm{C}\left(\mathrm{CH}_{3}\right)\right.$ $\left.\mathrm{COOCH}_{2}-\right), 1.95\left(\mathrm{~m}, 3 \mathrm{H},=\mathrm{C}\left(\mathrm{CH}_{3}\right)\right), 1.7-1.9(\mathrm{~m}, 4 \mathrm{H}$, $\left.-\mathrm{CH}_{2} \mathrm{CH}_{2}-\right), 1.50\left(\mathrm{~m}, 4 \mathrm{H},-\mathrm{OCH}_{2} \mathrm{CH}_{2}\left(\mathrm{CH}_{2}\right)_{2} \mathrm{CH}_{2}-\right.$ $\mathrm{CH}_{2} \mathrm{O}-$ ).

$A E M A-C_{60}$ (5). Following a similar reaction and purification procedure, 5 (dark brown powder), using 2-(4-azidobenzoyloxy)ethyl methacrylate and fullerene was prepared in $17 \%$ yield. ${ }^{1} \mathrm{H} \mathrm{NMR}\left(\mathrm{CS}_{2} / \mathrm{CDCl}_{3}=4 / 1\right)$ 8.18, 8.05 (dd, 2H, Ar), 7.70, 7.50 (dd, 2H, Ar), 6.12 (m, $\left.1 \mathrm{H}, \mathrm{CH}_{2}=\right), 5.58\left(\mathrm{~m}, 1 \mathrm{H}, \mathrm{CH}_{2}=\right), 4.4-4.6(\mathrm{~m}, 4 \mathrm{H}$, $\left.-\mathrm{OCH}_{2} \mathrm{CH}_{2} \mathrm{O}-\right), 1.95\left(\mathrm{~m}, 3 \mathrm{H},=\mathrm{C}\left(\mathrm{CH}_{3}\right)\right)$.

\section{Copolymerization}

Copolymerizations of fullerene monomers and $t$-BMA were carried out using azobis(isobutyronitrile) (AIBN) or phenylmagnesium bromide as an initiator. The fullerene monomer and initiator were placed in a polymerization ampoule and the contents were dried for $3 \mathrm{~h}$ under vacuum. Chlorobenzene and $t$-BMA were added to the ampoule by distillation under vacuum, and the ampoule was sealed off. The polymerization was started by heating to $60^{\circ} \mathrm{C}$ for the radical initiator or by adding phenylmagnesium bromide by breaking the glass seal. The polymer was separated from the content by gel permeation chromatography (GPC) with a preparative column $(20 \mathrm{~mm} \phi \times 60 \mathrm{~cm})$ using chloroform as an eluent. The fraction in the elution volume range from 40 to $64 \mathrm{ml}$ was collected as a polymer. The remaining fullerene containing monomer eluted at $86 \mathrm{ml}$. After evaporation of the eluent, the copolymer was purified by washing with methanol and hexane, followed by drying under vacuum.

\section{Measurements}

GPC was conducted using a JASCO BIP-I or JASCO 880-PU high pressure pump and a JASCO UV-970 detector (wavelength $330 \mathrm{~nm}$ ). Styrene-divinylbenzene gel beads ${ }^{17}$ were used as the stationary phase and toluene or chloroform as the eluent. Standard polystyrenes (Showdex) with $M_{w}$ of $1320-3040000$ were used as the references for molecular weight. ${ }^{1} \mathrm{H}$ and ${ }^{13} \mathrm{C}$ NMR measurements were performed on a JEOL $\alpha-500$ NMR spectrometer in deuterated chloroform or carbon disulfide using tetramethylsilane (TMS) as an internal standard.

\section{RESULTS AND DISCUSSION}

Strong nucleophiles like alkyllithium react with fullerene, ${ }^{18}$ but weaker nucleophile may not. We proved that when a weaker nucleophile like phenyl magnesium bromide is mixed with fullerene at a molar ratio of $1: 1$ in chlorobenzene and allowed to stand for $24 \mathrm{~h}$ at $30^{\circ} \mathrm{C}$ and the content is checked by HPLC using styrenedivinyl benzene gel beads as the stationary phase and toluene as the eluent, only $5 \%$ of phenyl magnesium bromide reacts with fullerene. Wudl et al. stated that a Grignard reagent readily reacts with fullerene, when excess Grignard reagent is present. ${ }^{19}$ The difference may be due to different reaction conditions. Thus, a vinyl monomer containing fullerene, polymerizable by the Grignard reagent, will provide a charm bracelet fullerene polymer, if the initiator concentration is carefully chosen.

A monomer, namely methacrylate containing fullerene, was synthesized as shown in Scheme 1. Figure 1 shows a GPC chart of the reaction mixture between 6-(4-azidobenzoyloxy)hexyl methacrylate and fullerene. New peaks at $30.4 \mathrm{~min}$ and earlier increased with decrease of fullerene at $39.6 \mathrm{~min}$. Judging from the elution time and change of each peak, it may be said that the peak at $30.4 \mathrm{~min}$ is ascribed to the fullerene containing one methacrylate group and those eluted earlier than 30.4 
min are due to fullerenes containing more than two methacrylate groups.

The fraction eluted at 30.4 min was collected by column chromatography using silica gel as the stationary phase and toluene as the eluent. The compound obtained $($ AHMA-C 60 ) had a molar absorption coefficient $(\varepsilon)$ of<smiles>C=C(C)[C+](C)C(=O)Cl</smiles>

(1)
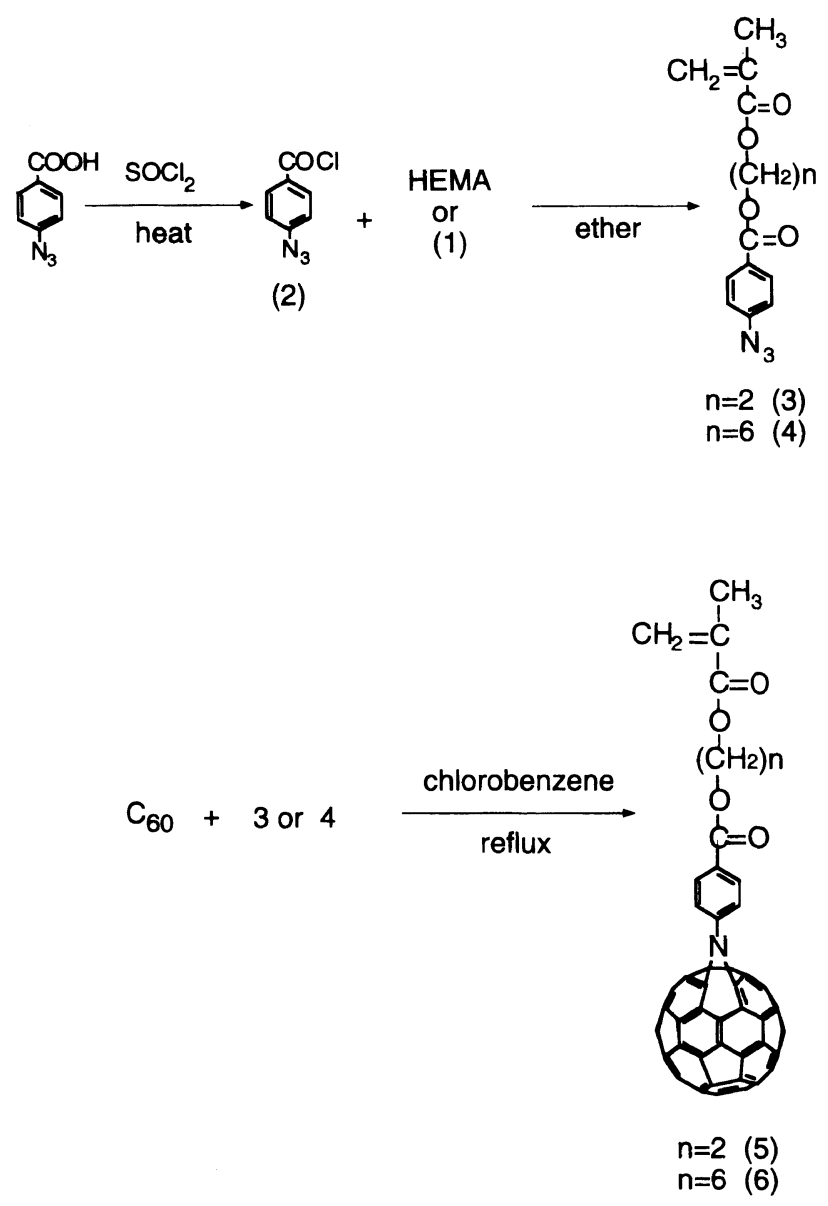

Scheme 1. Preparation of fullerene-containing monomer.

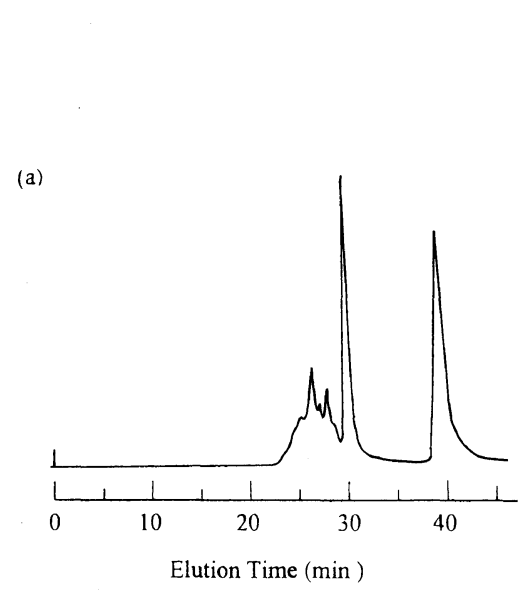

Figure 1. GPC charts of reaction product (a), purified product (b), and $\mathrm{C}_{60}$ (c).
$4.41 \times 10^{4}$ at $330 \mathrm{~nm}$ while fullerene showed $\varepsilon$ of $4.36 \times$ $10^{4}$. Taking these values into account, the time conversion of the reaction between 6-(4-azidobenzoyloxy)hexyl methacrylate and fullerene was determined by GPC as shown in Figure 2. The amount of AHMA-C 60 increased till $8 \mathrm{~h}$ and then leveled off. In contrast, fullerene was decreased continuously with increase of GPC peak eluted earlier than $29 \mathrm{~min}$. This means that $\mathrm{AHMA}-\mathrm{C}_{60}$ reacts with the azide compound resulting in the fullerene compound with more than two methacrylate units.

AHMA- $\mathrm{C}_{60}$ showed a parent peak at $\mathrm{m} / \mathrm{z}$ of 1024 , confirming that the product was a fullerene derivative with one methacrylate unit. Figure 3 shows ${ }^{1} \mathrm{H}$ NMR spectrum of AHMA-C 60 . The methacrylate residue of AHMA-C 60 shows signals due to $\alpha$-methyl proton at $1.96 \mathrm{ppm}$, and to olefinic protons at 5.57 and $6.10 \mathrm{ppm}$. The six methylene proton signals of the ester linkage appear at $4.38,4.18,1.80,1.77$, and $1.50 \mathrm{ppm}$. Two pairs of aromatic protons appear around 8.2 and $7.7 \mathrm{ppm}$. Each signal is split into two peaks. The intensity ratio of the peaks decreased from $3: 1$ at the $10 \mathrm{~h}$ reaction time to $2: 3$ at the $12 \mathrm{~h}$ reaction time during refluxing AHMA- $\mathrm{C}_{60}$ in chlorobenzene after the separation. Thus, AHMA- $\mathrm{C}_{60}$ may be a mixture of two thermally unstable isomers. Four isomers can be produced in the reaction, i.e., $[6,6]$ and $[5,6]$ addition products of azamethanofullerene and azafulleroid derivatives. ${ }^{20}[6,6]$ and $[5,6]$ addition products can be differentiated each other by the number of carbon signals; i.e., the former has 17 and the latter has 32 carbon signals. The presence of a ${ }^{13} \mathrm{C} \mathrm{NMR}$ signal near $80 \mathrm{ppm}$ distinguishes azamethanofullerene derivatives from azafulleroid derivatives. ${ }^{21}$ Figure 4 shows the ${ }^{13} \mathrm{C}$ NMR spectrum of AHMA-C 60 before and after refluxing. Carbon atoms of fullerene and phenyl groups resonated as 57 signals in the chemical shift range of 83 to 152 ppm. 21 signals ( 17 from $\mathrm{C}_{60}$ and 4 from phenyl) increased and 36 signals ( 32 from $C_{60}$ and 4 from phenyl) decreased with heating. The isomer increased by heating showed a signal at $83.45 \mathrm{ppm}$. Therefore, it may be concluded that the $[5,6]$ addition product of azafulleroid derivative is produced first, and then isomerized to the $[6,6]$ addition product of azamethanofullerene derivative. Table I summarizes ${ }^{13} \mathrm{C}$ NMR signals assigned for AHMA-C 60 . Similar results on the reaction product of fullerene with a diazomethane derivative were reported by Wudl et al. ${ }^{22}$

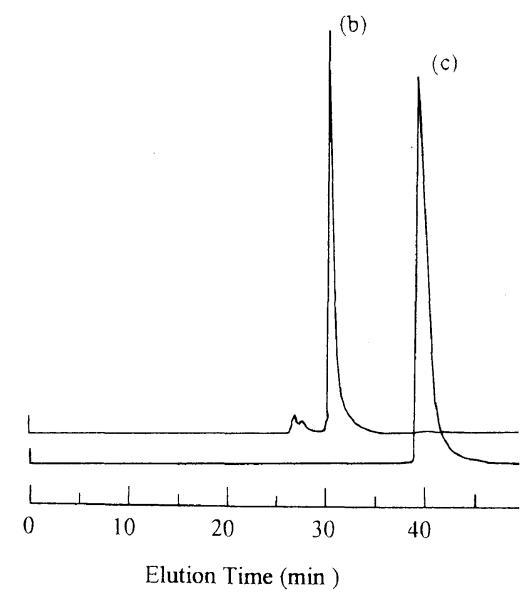




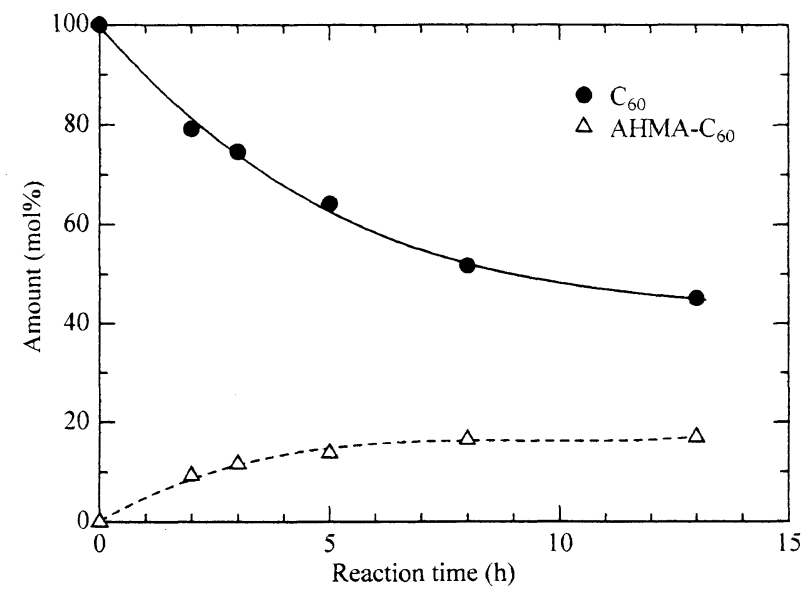

Figure 2. Change of relative amount of $\mathrm{C}_{60}$ and AHMA-C $\mathrm{C}_{60}$ during the reaction.

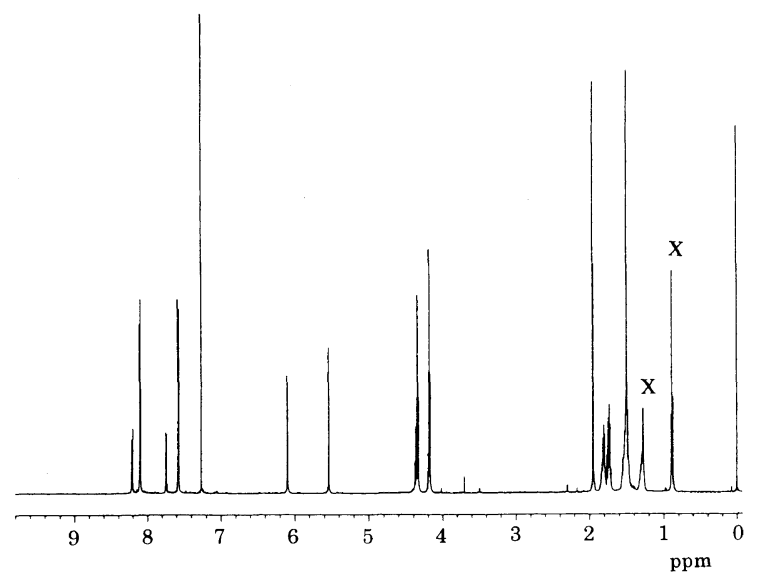

Figure 3. ${ }^{1} \mathrm{H}$ NMR spectrum of $\mathrm{AHMA}^{-\mathrm{C}_{60}}$ in $\mathrm{CDCl}_{3}$ at $50^{\circ} \mathrm{C} . \mathrm{X}$, hexane.
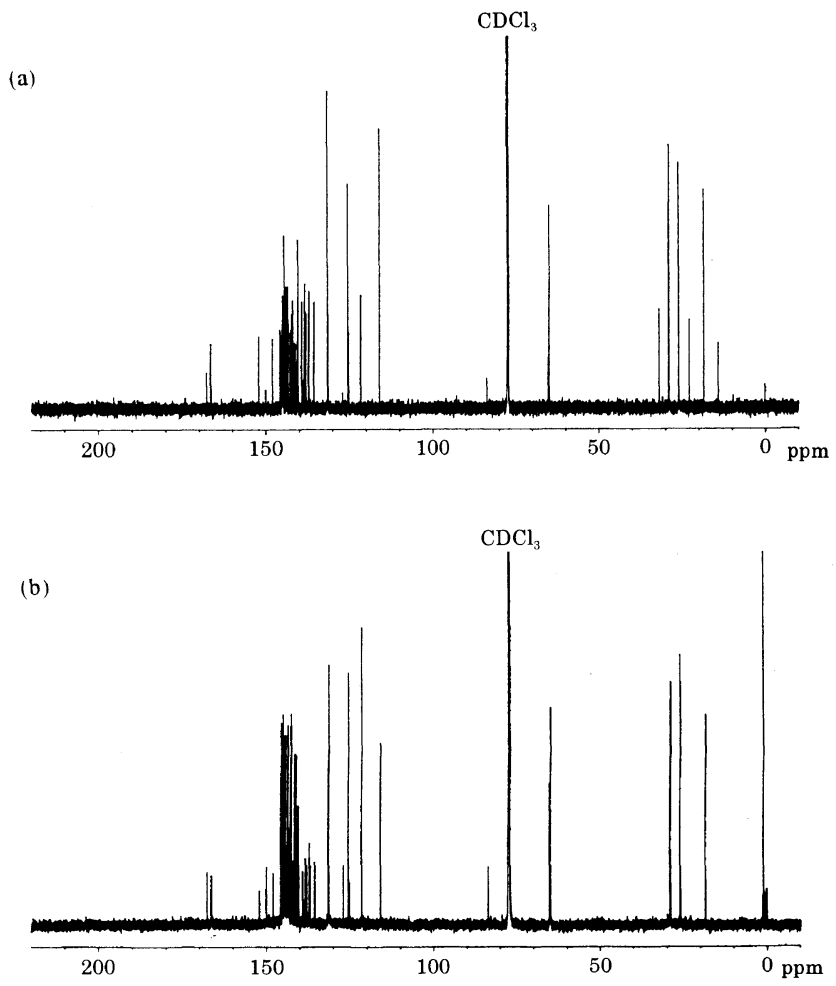

Figure 4. ${ }^{13} \mathrm{C}$ NMR spectra of AHMA-C ${ }_{60}$ before (a) and after (b) refluxing for $12 \mathrm{~h}$ in chlorobenzene (in $\mathrm{CDCl}_{3}$ at $50^{\circ} \mathrm{C}$ ).
Table I. ${ }^{13} \mathrm{C}$ NMR signals assigned to AHMA-C 60

\begin{tabular}{|c|c|c|c|}
\hline \multirow{2}{*}{ Assignment } & \multirow{2}{*}{ No. } & \multicolumn{2}{|c|}{ Chemical shift/ppm } \\
\hline & & {$[6,6]$ Addition $^{a}$} & {$[5,6]$ Addition $^{\mathrm{b}}$} \\
\hline $\mathrm{C}=\mathrm{O}$ & 11 & 165.37 & 165.30 \\
\hline \multirow{11}{*}{$\begin{array}{l}\text { Quaternary } \\
\text { carbon } \\
\left(\mathrm{C}_{60},\right. \\
\text { phenyl) }\end{array}$} & & $83.45,140.95,141.34$ & $124.91,135.25,136.79$ \\
\hline & 16 & $142.47,142.49,143.17$ & $137.76,138.10,138.61$, \\
\hline & 15 & 143.38, 143.42, 143.44, & $139.01,140.19,140.22$ \\
\hline & 12 & $144.16,144.28,144.52$ & $140.24,141.75,142.11$, \\
\hline & & $144.85,144.90,145.13$ & $143.11,143.32,143.54$ \\
\hline & & $145.18,155.50,145.58$ & $143.61,143.62,143.80$ \\
\hline & & 149.83 & $143.81,143.85,144.01$, \\
\hline & & & \\
\hline & & & $\begin{array}{l}144.57,144.62,144.76, \\
144.83,144.86,144.88\end{array}$ \\
\hline & & & $144.89,144.96,147.74$ \\
\hline & & & 151.93 \\
\hline \multicolumn{2}{|c|}{ Phenyl (C-H) 13, 14} & $124.41,131.17$ & $115.80,131.39$ \\
\hline $\mathrm{C}=\mathrm{O}$ & 4 & 166 & 6.68 \\
\hline $\mathrm{C}$ & 3 & 136 & 6.85 \\
\hline $\mathrm{CH}_{2}=$ & 2 & 125 & 5.25 \\
\hline \multirow[t]{3}{*}{$-\mathrm{CH}_{2-}^{-}$} & 5,10 & & $4.91,65.15$ \\
\hline & 6,9 & & $3.84,29.00$ \\
\hline & 7,8 & & $6.00,26.03$ \\
\hline $\mathrm{CH}_{3-}$ & 1 & & 3.45 \\
\hline
\end{tabular}

${ }^{a}$ Azamethanofullerence derivative. ${ }^{b}$ Azafulleroid derivative.

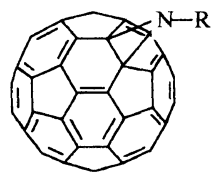

(16)

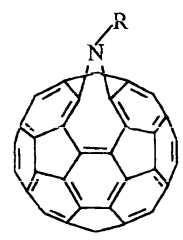

(16)

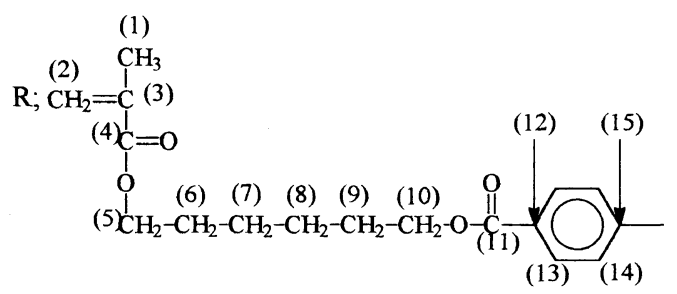

Fullerene and 2-(4-azidobenzoyloxy)ethyl methacrylate were reacted to obtain AEMA- $\mathrm{C}_{60}$ as a mixture of the two isomers. The solubilities of fullerene, AEMA- $\mathrm{C}_{60}$, and $\mathrm{AHMA}-\mathrm{C}_{60}$ in chlorobenzene were $0.004,0.004$, and $0.04 \mathrm{~mol} \mathrm{l}^{-1}$, respectively. Thus, owing to the introduction of a longer oligomethylene chain between fullerene and methacrylate unit, the solubility of the monomer increased 10 times. However, the solubility of each monomer was not high enough to homopolymerize. Thus, copolymerization was carried out with $t$-BMA because the bulky $t$-butyl group may protect the carbonyl group from nucleophilic attack of the anionic initiator. Chlorobenzene was used as solvent in the copolymerization since it is one of the best solvents for fullerene derivatives.

Table II lists the results of anionic copolymerization. The results of radical copolymerization are also included in this table for comparison. In the case of phenylmagnesium bromide catalyst, $t$-BMA gave a polymer in $85 \%$ yield at $25^{\circ} \mathrm{C}$. Polymer yield decreased to $44 \%$ by adding $1 \mathrm{~mol} \%$ of $\mathrm{AHMA}-\mathrm{C}_{60}$ to the feed monomer. This yield decrease may be attributed to the two carbon$y l$ groups in AHMA-C 60 , and the impurities in the 
H. Sato, D. Matsuda, and K. Ogino

Table II. Copolymerization of AHMA-C ${ }_{60}$ or AEMA- $\mathrm{C}_{60}$ with $t$-butyl methacrylate ${ }^{\mathrm{a}}$

\begin{tabular}{|c|c|c|c|c|c|c|c|c|}
\hline \multirow{2}{*}{ No. } & \multirow{2}{*}{$\frac{\text { AHMA-C }_{60}}{\mathrm{~mol}^{\mathrm{c}} \mathrm{c}^{\mathrm{c}}}$} & \multirow{2}{*}{$\frac{\text { AEMA-C }_{60}}{\mathrm{~mol}^{\mathrm{c}}}$} & \multirow{2}{*}{$\frac{\text { Initiator }}{\mathrm{mol} \%}$} & \multirow{2}{*}{$\frac{\text { Temp }}{{ }^{\circ} \mathrm{C}}$} & \multicolumn{2}{|c|}{ Molecular weight ${ }^{\mathrm{b}}$} & \multirow{2}{*}{$\begin{array}{c}\text { Yield } \\
\%\end{array}$} & \multirow{2}{*}{$\frac{\mathrm{C}_{60} \text { in copolymer }}{\mathrm{mol} \%}$} \\
\hline & & & & & $M_{n}$ & $M_{w} / M_{n}$ & & \\
\hline \multicolumn{9}{|c|}{ Initiator; $\mathrm{PhMgBr}$, polymerization time of $12 \mathrm{~h}$} \\
\hline 1 & - & - & 3.0 & 25 & 5400 & 1.52 & 85 & 0.0 \\
\hline 2 & 1.0 & - & 3.0 & 25 & 8900 & 2.90 & 44 & 1.2 \\
\hline 3 & 4.8 & - & 5.0 & -20 & 10800 & 3.07 & 85 & 5.0 \\
\hline 4 & 9.1 & & 3.0 & -20 & 13600 & 3.93 & 52 & 10.5 \\
\hline 5 & - & 1.0 & 3.0 & 25 & 4300 & 1.96 & 45 & 1.2 \\
\hline \multicolumn{9}{|c|}{ Initiator; AIBN, polymerization time of $24 \mathrm{~h}$} \\
\hline 6 & - & - & 2.0 & 60 & 16700 & 1.87 & 73 & 0.0 \\
\hline 7 & 1.0 & - & 2.0 & 60 & 1000 & 3.51 & 8 & 2.0 \\
\hline 8 & - & 1.0 & 2.0 & 60 & 2000 & 3.65 & 4 & 2.1 \\
\hline
\end{tabular}

${ }^{a}$ Solvent, chlorobenzene; $[t$-BMA $]=0.2 \mathrm{M}($ No. $1,5,6,8), 0.3 \mathrm{M}($ No. $2,3,4,7) . \quad{ }^{\mathrm{b}}$ Determined by GPC. $\quad{ }^{\mathrm{c}}$ Mole fraction of AEMA-C 60 or AHMA-C ${ }_{60}$ in feed.

(a)

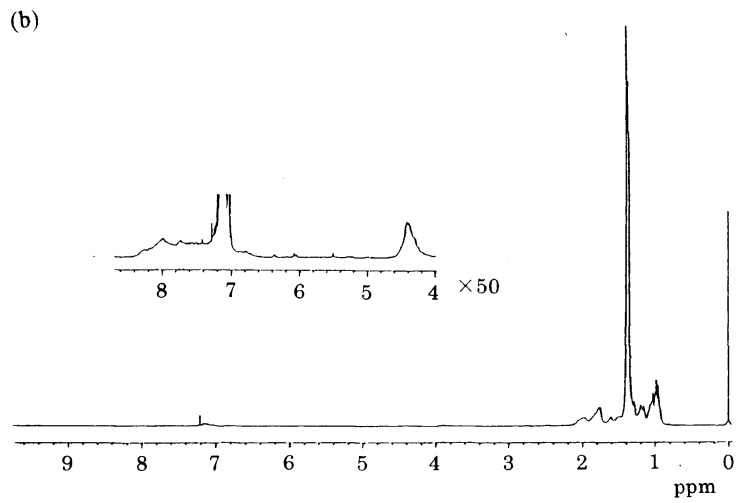

Figure 5. ${ }^{1} \mathrm{H}$ NMR spectra of copolymer of AHMA-C ${ }_{60}$ (a) and AEMA-C ${ }_{60}$ (b) with $t$-butyl methacrylate using phenylmagnesium bromide as an initiator (in $\mathrm{CDCl}_{3}$ at $50^{\circ} \mathrm{C}$ ).

monomer, which deactivated the initiator. By lowering the reaction temperature, copolymer having about $10 \%$ of fullerene unit was prepared. Similar results were also found with AEMA-C 60 , even though only $1 \%$ of this monomer was fed to the copolymerization system due to low solubility. The recoverd copolymers were brown powders, and soluble in a variety of organic solvents such as chloroform, THF, chlorobenzene, and tolune.

Copolymer yields were less than $8 \%$ for the radical initiator, while $t$-BMA homopolymer yields were more than $70 \%$. The radical copolymerization provided low molecular weight oligomers with molecular weights of 908
$1000-2000$, which were much lower than that of $t$-BMA homopolymer. In anionic copolymerization, such a large difference of molecular weight was not observed for the homopolymer and copolymers. These drastic changes in yields and molecular weights for radical copolymerization may be due to the fact that the fullerene unit acts as an inhibitor or degradative chain transfer reagent. Similar results are reported for the radical polymerization of methacrylate or styrene in the presence of fullerene. ${ }^{12}$

Figure 5 shows ${ }^{1} \mathrm{H}$ NMR spectra of copolymers prepared by the anionic initiator. The large peak around $1.5 \mathrm{ppm}$ was assigned to methyl proton of $t$-butyl group. Signals around 1 and 2 ppm were assigned to $\alpha$-methyl and main-chain methylene protons of the two monomer units. The monomer units containing fullerene were responsible for the small peaks in the lower chemical shift than $4 \mathrm{ppm}$. The signals for the methylene protons linked to ester oxygen appeared around $4.3 \mathrm{ppm}$ and those for aromatic protons did so around 7.5 and 8.1 ppm. The phenyl group of the initiator was observed in the chemical shift range of 7.0 to $7.4 \mathrm{ppm}$. Considering the signal intensity ratio of the peak around $4.3 \mathrm{ppm}$ and those in the range of 0.8 to $2.2 \mathrm{ppm}$, chemical composition of each copolymer was determined. The composition of copolymer prepared by the anionic initiator was almost equal to the composition of the feed monomer. Olefinic proton signals of unreacted methacrylate residue were less than $5 \%$ of AHMA-C 60 or AEMA-C 60 unit incorporated in the copolymer. These results indicate that almost all fullerene containing monomer was incorporated via the vinyl polymerization of methacrylate residue, not via the chain transfer to the fullerene unit, and consequently the linear charm bracelet fullerene polymers were obtained.

Figure 6 shows ${ }^{1} \mathrm{H}$ NMR spectra of the copolymers prepared by the radical initiator. The monomer units containing fullerene were responsible for the small signals around 4.5 and $8 \mathrm{ppm}$. The amount of the monomer residue containing fullerene unit was about two times the amount of monomer feed. Contrary to the copolymers prepared by the anionic initiator, these copolymers showed strong signals of vinyl protons at 5.5 and $6.1 \mathrm{ppm}$. The amounts of vinyl groups were more than $95 \%$ of the fullerene monomer units incorporated into the polymer. Therefore, these monomer units are incorporated not by the vinyl polymerization but by the 


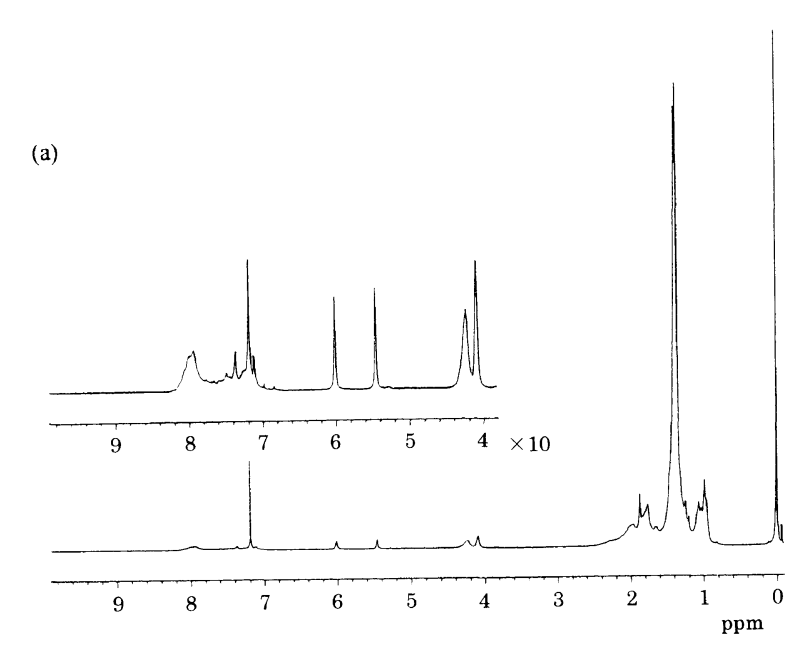

(b)

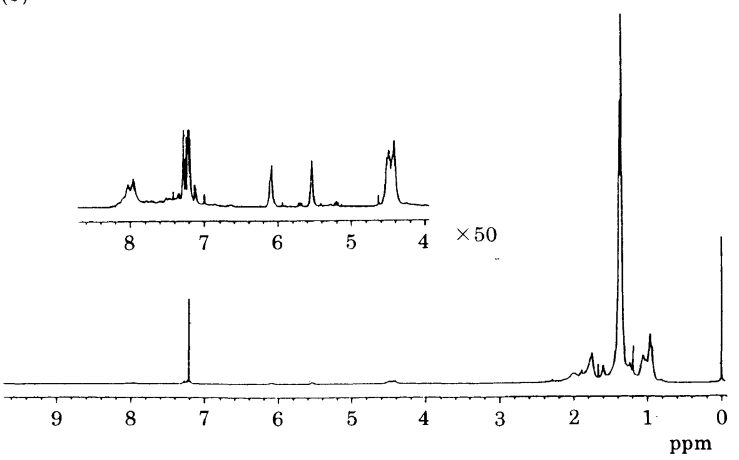

Figure 6. ${ }^{1} \mathrm{H}$ NMR spectra of copolymer of AHMA-C ${ }_{60}$ (a) and AEMA- $\mathrm{C}_{60}$ (b) with $t$-butyl methacrylate using AIBN as an initiator (in $\mathrm{CDCl}_{3}$ at $50^{\circ} \mathrm{C}$ )

chain transfer reaction to the fullerene residue and the fullerene unit is much more reactive to radicals than methacrylate group.

\section{CONCLUSIONS}

To prepare a charm bracelet type fullerene polymer, two types of methacrylate monomers containing fullerene (AHMA-C 60 or AEMA-C 60 ) were synthesized by reaction of fullerene and 4-azidobenzoyloxy-hexyl or -ethyl methacrylate, respectively. According to the ${ }^{1} \mathrm{H}$ and ${ }^{13} \mathrm{C}$ NMR spectroscopic analysis of monomers, they were a mixture of $[6,6]$ bridged azamethanofullerene derivative and azafulleroid derivative resulting from $[5,6]$ additions. These monomers were copolymerized with $t$ butyl methacrylate. In the case of anionic copolymerization by phenylmagnesium bromide, each monomer was incorporated in the polymer chain via vinyl group, and thus a charm bracelet type fullerene polymer was obtained. The radical copolymerization gave polymers containing almost equal amounts of the vinyl group to the fullerene monomer and molecular weight and yield decreased considerably, indicating that the fullerene unit played a role of an inhibitor or a degradative chain transfer agent. Thus, anionic initiator or chain end are more reactive to the methacrylate unit than fullerene unit, while radical species show the reverse reactivity toward both units.

Acknowledgment. We should like to thank Dr. A. Karomokar for valuable discussions.

\section{REFERENCES}

1. H. W. Kroto, J. R. Heath, S. C. O'Brine, R. F. Curl, and R. E. Smalley, Nature, 318, 162 (1985).

2. W. Krätschmer, L. D. Lamb, K. Fostiroopoulos, and D. R Huffman, Nature, 347, 354 (1990).

3. (a) A. Hamed, M. Rasmussen, and P. H. Hor, Phys. Rev. B., Rapid Commun., 48, 14760 (1991). (b) K. Yoshino, T. Akashi, K. Yoshimoto, S. Morita, T. Kawai, and A. A. Zakhidov, Jpn. J. Appl. Phys., 34, L 127 (1995). (c) N. S. Sarifitci, L. Smilowitz, A. J. Heeger, and F. Wudl, Science, 258, 1474 (1992).

4. Y. Wang, Nature, 356, 585 (1992).

5. P. M. Allemand, K. C. Khemani, A. K. Koch, F. Wuld, K Holcxwr, S. Donovan, G. Gruner, and J. D. Thompson, Science, 253, 301 (1991).

6. I. Amato, Science, 254, 30 (1991).

7. (a) A. M. Rao, P. Zhou, Kai-An Wang, G. T. Hager, J. N Holden, Y. Wang, W.-T. Lee, Xiang-Xin Bi, P. C. Eklumd, D. S. Cornett, M. A. Duncan, and I. J. Amster, Science, 259, 955 (1993). (b) Y. Iwasa, T. Arima, R. M. Fleming, T. Siegrist, O. Zhou, R. C. Haddon, L. J. Rothberg, K. B. Lyons, H. L. Carter, Jr., A. F. Hebard, R. Tycko, G. Dabbagh, J. J. Krajewski, G. A. Thomas, and T. Yagi, Science, 264, 1570 (1994).

8. D. A. Loy and R. A. Assink, J. Am. Chem. Soc., 114, 3977 (1992)

9. N. Manolova, I. Rashknov, H. Van Damme, and F. Beguin, Polym. Bull., 33, 175 (1994).

10. J. Li, T. Yoshizawa, M. Ikuta, M. Ozawa, K. Nakahara, T. Hasegawa, K. Kitazawa, M. Hayashi, K. Kinbara, M. Nohara, and K. Saigo, Chem. Lett., 1037 (1997).

11. M. Taki, S. Takigami, Y. Watanabe, Y. Nakamura, and J. Nishimura, Polym. J., 29, 1020 (1997).

12. (a) T. Cao and S. E. Webber, Macromoleculs, 28, 3741 (1995). (b) C. E. Bunker, G. E. Lawson, and Y.-P. Sun, Macromoleculs, 28, 3744 (1995). (c) A. G. Camp, A. Lary, and W. T. Ford, Macromoleculs, 28, 7959 (1995).

13. S. Shi, K. C. Khemani, Q. C. Li, and F. Wudl, J. Am. Chem. Soc., 114, 10656 (1992).

14. M. Berrada, Y. Hashimoto, and S. Miyata, Chem. Mater., 6, 2023 (1994).

15. C. J. Hawker, Macromolecules, 27, 4836 (1994).

16. K. E. Geckeler and A. Hirsch, J. Am. Chem. Soc., 115, 3850 (1993).

17. K. Ogino, H. Sato, K. Tsuchiya, H. Suzuki, and S. Moriguchi, J. Chromatogr. A, 699, 59 (1995).

18. A. Hirsch, A. Soi, and H. R. Karfunkel, Angew. Chem. Int. Ed. Engl., 31, 766 (1991).

19. F. Wudl, A. Hirsch, K. C. Khemani, T. Suzuki, P.-M. Allemand, A. Koch, H. Eckert, G. Srdanov, and H. M. Webb, "Fullerenes: Synthesis, Properties, and Chemistry of Large Carbon Clusters," American Chemical Society Symposium Series, 481, 1992, p 161.

20. (a) M. Prato, Q. C. Li, F. Wudl, and V. Lucchini, J. Am. Chem. Soc., 115, 1148 (1993). (b) L. Isaacs and F. Diederich, Helv. Chim. Acta, 76, 2454 (1993). (c) T. Ishida, K. Tanaka, and T. Nogami, Chem. Lett., 561 (1994).

21. M. R. Banks, J. I. G. Cadogan, I. Gosney, P. K. G. Hodgson, P. R. R. Langridge-Smith, and D. W. H. Rankin, J. Chem. Soc., Chem. Commun., 1365 (1994).

22. M. Prato, V. Lucchini, M. Maggini, E. Stimpfl, G. Scorrano, M. Eiermann, T. Suzuki, and F. Wudl, J. Am. Chem. Soc., 115, 8479 (1993). 